\title{
A emergência de uma Moda contemporânea
}

Humberto Pinheiro Lopes é Doutor e especialista em Estudos Contemporâneos pelo Instituto de Investigação Interdisciplinar (IIIUC) da Universidade ade Coimbra (UC) com título de doutor revalidado em Design pela Escola de Ciências, Arquitetura e Design da Universidade Anhembi Morumbi (UAM). Mestre em Cultura Visual pela Faculdade de Artes Visuais (FAV) da Universidade Federal de Goiás (UFG). Bacharel em Estilismo e Moda pelo Instituto de Cultura e Arte (ICA) da Universidade Federal do Ceará (UFC). É professor do curso técnico de Produção de Moda da Escola Técnica de Artes (ETA) da Universidade Federal de Alagoas (UFAL).

<humberto.lopes@ichca.ufal.br> ORCID: 0000-0002-2972-6310
Resumo Este artigo problematiza a emergência de teorias contemporâneas do design de moda com a finalidade de aplacar discursos que defendem a luta de classes, ao caracterizar a Moda como um fenômeno simplista, que ocorre da imitação dos mais ricos para os mais pobres. Esta é uma discussão que prioriza o pensamento sobre teorias contemporâneas que adotam uma postura à exaltação da subjetividade. Como proposta das reflexões, este estudo defende que as teorias contemporâneas para o design de moda acastelam posições contrárias a esse modelo de luta de classes, ao sugerirem habilmente uma dinâmica dualista, ao afirmar posições e modelos contraditórios.

Palavras chave Design, Moda, Teoria, Contemporâneo. 


\section{An emergence of contemporary fashion}

Abstract This paper discusses an emergence of contemporary theories of fashion design in order to minimize discourses that defend class conflict, which characterize Fashion as a simplistic phenomenon that occurs from the imitation of the richest to the poorest. This is a discussion that prioritizes thinking about contemporary theories which adopt a stance towards the exaltation of subjectivity. As a proposal for reflections, this study argues that contemporary theories for fashion design point out positions contrary to this model of class conflict.

Keywords Design, Fashion, Theory, Contemporary.

\section{El surgimiento de la moda contemporánea}

Resumen Este artículo discute el surgimiento de teorías contemporáneas del diseno de moda para aplacar los discursos que defienden la lucha de clases, que caracterizan a la moda como un fenómeno simplista que ocurre desde la imitación de los más ricos a los más pobres. Esta es una discusión que prioriza el pensamiento sobre las teorías contemporáneas que adoptan una postura hacia la exaltación de la subjetividad. Como una propuesta de reflexión, este estudio argumenta que las teorías contemporáneas para el diseño de moda presentan posiciones contrarias a este modelo de lucha de clases, al sugerir hábilmente una dinámica dualista, al afirmar posiciones y modelos contradictorios.

Palabras clave Diseño, Moda, Teoría, Contemporáneo. 


\section{Pontos introdutórios}

Este artigo é parte duma pesquisa (LOPES, 2017) que foi vinculada ao Doutoramento em Estudos Contemporâneos (DEC) do Centro de Estudos Interdisciplinares do Século XX (CEIS20) do Instituto de Investigação Interdisciplinar (IIIUC) da Universidade de Coimbra (UC) entre 2013 e 2018. A investigação doutoral avaliou como e com quais implicações produtos copiados de moda são comercializados mediante a criminalização corroborada pela legislação e por uma censura social revelada pela cultura ${ }^{1}$.

Neste excerto, foi elegida uma parte da pesquisa supracitada relativa à compreensão do design de moda implicando sobre uma dinâmica que atentou a um componente imprevisível às teorias da imitação. Nessa perspectiva, é possível questionar uma tradição secular que defende a teoria da luta de classes, baseada no efeito trickle down, que se popularizou no início do século XX. Por meio duma pesquisa bibliográfica, são levantadas discussões a fim de questionar a luta de classes com base na reflexão de que o design de moda particulariza-se mediante um elemento de força expandida e imprevisível. Ao adotar um conceito expandido, o design de moda reflete uma articulação entre diversos campos, como abordam Mesquita (2016) e Serra e Mesquita (2019), buscando uma composição dialógica e interdisciplinar entre diferentes áreas. Portanto, este artigo, analisa as teorias contemporâneas do design de moda com o propósito de arrazoar uma aproximação dum discurso que rejeita a teoria da luta de classes para alçar o design de moda frente à expansão da subjetividade. Conforme Meyer (2010), citando Friedman (2003), a teoria do design baseia-se num contexto inter/transdisciplinar. Consoante Bonfim (1997), tal contexto deve ater-se para o contato do design com as diferentes áreas do conhecimento científico. 0 design de moda adentra esse contexto, ao observar implicâncias culturais, econômicas, políticas e sociais. Para este recorte, os Fashion Studies (Estudos sobre Moda) compreendem a trans/interdisciplinaridade, como defendem Rocamora e Smelik (2015), ao analisarem as teorias contemporâneas do design de moda.

O design de moda cobre cada vez mais setores duma organização socioeconômica mundial (BARNARD, 2003). Mora, Rocamora e Volonté (2014) consideram que o caráter interdisciplinar do design de moda é evocado quando expõem que os Fashion Studies relacionam-se com uma variação de disciplinas que incluem a antropologia, os estudos culturais, a história, a psicologia e a sociologia. Os autores acrescentam que o valor dos Fashion Studies serve como uma plataforma para interrogar o passado e o presente das sociedades, um testemunho de que sua riqueza como um tópico se empenha em questões variadas, ao atravessarem as identidades políticas, a globalização, a sustentabilidade, a tecnologia e o trabalho.

o domínio operado pelo design de moda é extensivo. Limitá-lo a um campo que analisa somente aparência é tornar inadequada uma ideia de sua abrangência (BLUMER, 1969). Marques (2014) afirma que a Moda é flutuante, uma vez que é apropriada por diferentes conhecimentos, inclusive, 
o design. A autora reconhece na Moda uma significância universal, optando percebê-la também como um fenômeno social, inserido num contexto histórico, afetado por fatores econômicos e políticos. A Moda é uma esfera de produção ideológica e intelectual no que tange à produção de significados percebidos na coletividade. A Moda é uma (re)reprodução social permanente (GODART, 2010). As mudanças que ocorrem na disseminação da Moda traçam as diferenças entre estilos de vida, etnia e gênero. Isso evidencia como as mudanças nas relações sociais indicam tensões entre diferentes grupos que apresentam diferentes modos de ser e viver (CRANE, 2000). 0 design de moda reflete um momento histórico de tensão que aponta a segregação de grupos sociais privilegiados, ao posicionar modelos aceitos e quais os objetos devem ser adequadamente consumidos. Além do mais, o design de moda ingressa no núcleo dos discursos econômicos focados nos trabalhos criativos e culturais como um dos maiores condutores das economias desenvolvidas. Embora o design de moda permaneça como uma entidade cultural, esse alinhamento com a economia tem auxiliado a legitimá-lo perante os círculos políticos (ENTWISTLE, 2015). Tal legitimação reforça o discurso perante um poder que revela sua aproximação com a realidade de grupos socialmente dominantes. Dessa forma, a discussão sobre uma teoria contemporânea para o design de moda tenta transcender tal realidade e horizontalizar sua perspectiva.

0 artigo está dividido em dois tópicos: "Contextualizando pelo viés da Moda e da moda" aborda a diferença entre as palavras "Moda" e "moda", ao observar que a primeira variante diz respeito ao fenômeno referente à dinâmica social sobre gostos e modos de ser e viver, enquanto a segunda atenta para fenômenos insulados referentes a situações passageiras e temporais; e "A Moda contemporânea" acastela a emergência de teorias contemporâneas para o design de moda, ao refutar uma pensamento tradicional e simplista que mantém a dimensão de teorias baseadas na luta de classes. Nas considerações finais, são tecidas reflexões que se centram em afirmar uma emergência da teoria de moda contemporânea, ao priorizar a exaltação da subjetividade, refutando a estabilidade de normas sociais.

\section{Contextualizando pelo viés da Moda e da moda}

Grafada com inicial maiúscula, a palavra Moda faz referência ao fenômeno correspondente a uma dinâmica que se atém aos gostos, à maneira de viver, ao modo de vestir etc. A lógica da Moda compreende uma inovação contínua em desfavor da tendência passada: "Para além da exaltação do variar a aparência é a afirmação da ligação entre a subjetividade e o vestir, a principal força" (MESQUITA, 2008, p. 106) que se alia à constante renovação. As práticas e os costumes vestimentares representam uma parte significativa da lógica do fenômeno, abrangendo uma estrutura desencadeada por uma obsolescência industrial programada ${ }^{2}$ (MOTA, 2006) ou por mo- 
vimentos independentes no seio das subculturas. Partindo duma (re)atualização de ferramentas, ideias e mecanismos, a produção dessa indústria implica em atualizar a cultura material duma sociedade com o intuito de acompanhar o dinamismo da cultura. Isso desencadeia no capitalismo uma obsolescência condicionada pelo mercado (BRANDINI, 2007), difundindo e descartando materialidade e imaterialidade.

Conforme Kawamura (2005), a Moda é tratada usualmente como futilidade por estar relacionada a questões de aparência. A Moda pode ser tachada a partir de aspectos superficiais não vinculados a um posicionamento intelectual. A autora aponta que a Moda pode ser considerada como socialmente frívola, entretanto não é sociologicamente trivial. Moda é o resultado de um grande acordo de influência, ao determinar coletivamente uma estrutura social. A Moda representa um processo complexo de individualização e socialização que relaciona forças econômicas, políticas e sociais, ao criar uma relevante forma de dinamismo. Outro fator que diminui os discursos sobre a Moda incide na diferença de gêneros: desde o século XIX, a Moda é um assunto que se relaciona gradativamente ao universo feminino (SOUZA, 1987). Apesar disso, na maior parte de sua história, a Moda tem sido mais importante para o homem do que para a mulher (RIELLO, 2016). Enquanto o homem é definido pela ocupação profissional, o papel social da mulher é discutido dentro duma estrutura que envolve seus interesses por uma obsessão à beleza, temática que se insere nos processos de reconhecimento simbólico da Moda. A devoção à moda pela mulher é apresentada como uma de suas fraquezas. Kawamura (2005) complementa que parte do debate feminista sobre vestimenta indica que o universo ligado à Moda tende a ser construído como um processo opressor desfavorável à mulher.

Iniciando por letra minúscula, "moda" aponta fenômenos insulados da Moda dentro duma dimensão temporal, alcançando uma posição a ser imitada, desde que reconhecida consensualmente, como por exemplo, um corte de cabelo difundido por uma celebridade ou uma peça de roupa vestida por um cantor famoso (MESQUITA, 2010; LOPES, 2012, 2014), propondo cânones de beleza e aceitabilidade social. Representando uma indústria, a moda é composta por empresas que se ocupam da criação, do desenvolvimento e da comercialização de acessórios, calçados, cosméticos, têxteis e vestuário (KNOLL; ECHEVERRIA, 2014). Os produtos dessa indústria são fabricados em meio a um processo de constante atualização, a fim de acompanhar os padrões de estética, modelos de beleza, praticidade e uso.

Os termos "moda" e "roupas" tendem a ser usados como sinônimos. Contudo, trata-se dum desvio edificado historicamente, instituindo a ideia de que moda e vestuário são sinônimos (MARQUES, 2014). Apesar disso, a palavra "moda" tem sido usada para referir-se à aparência, às roupas e a estilo. Mesquita (2008) indica que o estilo é o resultado das escolhas de vestuário e interferências sobre o corpo. Ademais, estilo admite a noção concernente ao termo atitude, que indica um conjunto de aspectos que varia da postura à gestualidade, "passando por diversas outras características ligadas ao comportamento, assim como preferências relativas à música, à 
literatura, aos hábitos de lazer etc. que, por sua vez, também se conectam a uma gama de produtos, marcas e locais de compra" (MESQUITA, 2008, p. 106). Quando se aborda sobre o estilo de vida, refere-se a um conceito que descreve "formas padronizadas de consumo no âmbito da alimentação, do vestuário, do lazer, entre outros, de um determinado grupo social" (BARBOSA, 2008, p. 17). Para Brandini (2007), o estilo de roupa assume a representação de hierarquias e relações de poder, ao partilhar as posições sociais nos territórios reais e virtuais. De acordo com Riello (2016), moda diferencia-se de estilo porque a primeira é um fenômeno coletivo influenciado pela indústria, enquanto o segundo manifesta uma expressão pessoal interiorizada. Em relação às roupas, estas passam por um processo de transformação para serem rotuladas como moda, o que incide em reconhecer as diferentes etapas de produção da indústria, da comercialização no mercado e da valorização simbólica na cultura.

Consoante Kawamura (2005), Moda é um conceito que separa ele mesmo das outras palavras utilizadas geralmente como sinônimo de moda, tais como aparência, estilo, roupas e vestuário. Essas palavras referem-se a objetos tangíveis, enquanto a moda é um objeto intangível, constituindo-se a partir dos elementos invisíveis incluídos nas roupas. Para a autora, a diferença entre moda e roupas torna-se divergente quando defende que a primeira se constitui de imaterialidade e as outras correspondem a objetos materiais. As roupas são a forma como pode ser manifestada a moda. A moda não é desenvolvida por um único agente individual, todavia por todos aqueles envolvidos na sua produção, tornando-a uma atividade coletiva. Por isso, a autora alerta que um comportamento ou uma vestimenta somente se tornam moda quando uma larga proporção de pessoas adota um novo estilo, reconhecendo sua conformidade e igualdade entre seus pares. Para que isso ocorra, Kawamura (2005) defende que o público acredita ou deseja acreditar que está vestindo e consumindo moda e não apenas roupas.

A partir dessas constatações, o design de moda dirige-se a um exercício intelectual, ao dar voz a elementos despercebidos, além de permitir uma reflexão sobre aspectos que redirecionam caminhos sociais (BRANDINI, 2007). Observando a diferença suscitada entre "Moda" e "moda", é proposto adiante um reconhecimento sobre os aspectos fundamentais da imitação na Moda contemporânea, o fenômeno, a fim de que se perceba um fator de expansão e imprevisibilidade própria do dinamismo de sua estrutura. É uma discussão que pauta o entendimento da emergência duma teoria contemporânea para o design de moda, que explica os direcionamentos da vida social perante o enaltecimento da subjetividade. 


\section{A Moda contemporânea}

As teorias sobre a imitação reconhecidas desde o século XIX são centradas nas unidireções. Isso que dizer que são verticais. Popularizaram-se no início do século XX, sobretudo, com a perspectiva do efeito trickle down. Esse efeito segue uma estrutura que se baseia a partir de modelos propostos pela difusão de conceitos dominantes das classes mais ricas (BALDINI, 2006). A partir dessas classes, a Moda dirige-se de forma gradativa às classes mais pobres por meio duma competição social. Compõe uma estrutura de imitação e diferenciação de difusão vertical, ao apontar um modelo que, sobremaneira, segue uma direção superior para uma inferior, reconhecendo-se pela chamada luta de classes. Baldini (2006) destaca que o efeito trickle down é um modelo que surge como aquele de difusão mais célebre, ao ser defendido a partir do século XVIII por pensadores como Kant (1994), Mandeville (1987), Simmel (1957, 2014), Spencer (1967), Tarde (1890) e Veblen (1915). As teorias que defendem uma projeção vertical apontam uma diferença, ao propor que a categoria inovadora é oposta a que copia. Conforme Pelbart (2000), o esquema de luta de classes é limitado, pois a imitação ocorre diante da expressão da subjetividade.

Enquanto um conceito, a Moda mudou historicamente. No século XV, representa algo diferente dos últimos dois séculos, bem como vai ganhando modelos de diferente acepção na atualidade. Enquanto no século XV, Moda foi um indicador de privilégio monopolizado praticamente pela aristocracia, no século XX, o panorama muda quando mais pessoas passam a ter mais acesso ao consumo (KAWAMURA, 2005). Na atualidade, a circulação de informações e sentidos aplacam resistências sociais às mudanças, indicando que o acesso ao consumo vai relacionando-se à expressão da individualidade. Logo, teorias da imitação que defendem a luta de classes não conseguem se adequar à cadeia multifocal relativa à Moda contemporânea, introduzindo "no tempo uma peculiar descontinuidade, que o divide segundo a sua atualidade ou inatualidade, o seu estar ou o seu não-estar-mais-na-moda" (AGAMBEN, 2009, p. 66). Para Agamben (2009), a Moda torna-se inapreensível porque seu tempo está adiantado a si mesmo e também atrasado. A Moda pode erigir "aquilo que inexoravelmente dividiu, rechamar, re-evocar e revitalizar aquilo mesmo que tinha declarado morto" (AGAMBEN, 2009, p. 69). A Moda constitui-se por fragmentos do tempo que representam a descontinuidade defendida por Agamben (2009). $O$ autor reconhece a contemporaneidade diante de uma característica moderna e arcaica, a qual percebe a origem constituída por um balanço entre a distância e a proximidade. Essa origem pulsa com mais força no presente, ainda que não se possa alcançá-la. A caracterização das sociedades contemporâneas sugere uma transformação nos relacionamentos entre os diferentes elementos da estrutura social e da natureza e do papel da cultura (CRANE, 2000). Considerando a descontinuidade alçada por Agamben (2000) e a transformação dos relacionamentos nas sociedades contemporâneas, o funcionamento da Moda mostra uma diferença em relação às teorias que defendem as unidireções como modo de difusão deste fenômeno. 
A proposta de Agamben (2009) sobre a ideia de descontinuidade é defendida por outros autores com abordagens diferentes, tais como Lipovetsky (2009), Mesquita $(2000,2010)$ e, em alguma medida, Preciosa (2005) e Svendsen $(2006,2010)$. Além disso, esses autores revelam que a Moda é um fenômeno que reúne condições culturais evidenciadas em todos os aspectos da vida social: um horizonte de mixagens evocado pela maior acessibilidade a bens de consumo. Em virtude desse horizonte, a difusão da Moda não se limita a uma prática linear que decorre da troca de valores entre dois pontos extremos, como defendem as teorias das unidireções. A Moda segue direções indistintas. Não é tão fácil prever o começo nem o fim dessas rotas.

Nesse trajeto, tanto podem surgir rumos inacabados como existir a possibilidade da construção de itinerários não previstos e da intromissão dum caos agenciador que, no pensamento de Preciosa (2005, p. 28), se sumariza a uma lógica onde "tudo que existe é um tornar-se constante". Conforme a autora, as interpretações simplificadoras da vida podem levar a outros roteiros que contemplem o exercício da subjetividade. Tal qual esse roteiro, o destino (se é que há um) da Moda ambienta-se pela lógica da subjetivação e da descontinuidade: "a imagem que me vem agora à lembrança é de uma enorme manta urdida coletivamente, cujos desenhos são sempre irregulares e provisórios" (PRECIOSA, 2005, p. 30). Germinando-se por fraturas ao longo da viagem, essas direções ampliam-se para uma gama de caminhos, tomando atalhos que não estavam previstos.

Os atalhos podem ser configurados por uma ideia de que Moda é informação: "promove a migração de produtos de um contexto para outro, com adaptações, relançamentos ou cópias, reciclando os mesmos pontos de partida" (MOTTA, 2011, p. 139). A ideia que faz Motta (2011) sobre esses pontos de partida é reconhecida pela forma como a Moda se difunde, por intermédio duma informação que se tem por direção um caminho alterado pelo tempo. Isto é, caminhos que ampliam as possibilidades de direção da propagação da Moda com passagens fragmentadas. A estrutura da Moda gera atalhos que fraturam qualquer lógica já construída.

Nesses caminhos, os atalhos podem igualar-se à mutação vertiginosa parafraseada por Pelbart (2011). A mutação é desorientada a ponto de alterar a relação com o passado, a experiência com o presente e a ideia de futuro. É uma temporalidade mutante exacerbada pelo plano tecnossocial, modificando a vivência do instante e a fantasia da eternidade deslocada pela instantaneidade do tempo. Pelbart (2000) descarta a linearidade do tempo considerando uma massa que se move, comparando-a às placas da crosta terrestre, ao reajustarem-se a cada movimento. 0 tamanho do abalo sísmico reajusta o tempo a uma configuração indefinida. Conforme for a grandiosidade do reajuste, mais elusiva será a configuração: a "navegação no tempo ganhou aspectos inusitados. Já não navegamos num rio do tempo, que vai de uma origem a um fim, mas fluímos num redemoinho turbulento, indeterminado, caótico. A direção do tempo se dilui a olhos vistos" (PELBART, 2011, p. 76). A flecha que direciona sucessiva, progressiva e cronolo- 
gicamente uma das formas possíveis de tempo sofre inflexões na direção e intensidades de cunho implosivos que fraturam lógicas lineares (PELBART, 2000). 0 tempo sofre uma alteração na velocidade da informação, rompendo-se com fraturas, fazendo surgir atalhos imprevistos ${ }^{3}$.

A mutação vertiginosa trilha caminhos contíguos à propagação da Moda consumada designada por Lipovetsky (2009), caracterizando tais rompimentos. A Moda consumada mostra indícios de que a luta de classes não propulsiona o impulso de imitação de forma dominante, compreendendo um período em que a elite deixa de ter privilégios de exclusividade. Mais pessoas passam a ter acesso a bens materiais e imateriais, mesmo que em graus diferentes. Svendsen (2010) aproxima-se de Lipovetsky (2009) quando defende que a Moda se torna mais uma questão de escolha individual do que submissão às diretrizes dum centro homogeneizador e difusor de tendências: "o estilo original não é mais privilégio do luxo, todos os produtos são doravante repensados tendo em vista uma aparência sedutora" (LIPOVETSKY, 2009, p. 189). A crítica lipovetskyana incide em tratar sobre a diminuição e a dependência em relação às normas sociais: há uma liberação das correntes de imitação que vão contra à luta de classes. Svendsen (2006) alega que é mais difícil reconhecer as características que definem a posição social, pois a individualização desfavorece a estabilidade das normas sociais. Lipovetsky (2009) harmoniza ao considerar que o consumo não está livre da competição social. Não obstante, esse autor defende uma redução do estatuto das normas sociais, apesar da continuidade da valorização dos produtos do mercado de luxo, revelando a manutenção dum código de diferenciação social. Na estrutura da Moda, a imitação é menos dependente do estatuto de diferenciação social, pois se converge à ascensão do individualismo. A luta de classes torna-se uma questão em segundo plano, uma vez que a abertura às novidades e à diversificação de estilos são forças propulsoras para os movimentos da imitação. Essa surge como uma resposta da apoteose dos valores culturais individualizados pela expressão do eu. Lipovetsky (2009) tenta estabelecer um equilíbrio entre a persistência da diferenciação social e a realização pessoal em favor de motivações íntimas e da gratificação do prazer.

A noção de Moda expandida ${ }^{4}$ considerada por Mesquita (2010) retrata um momento em que os modos de funcionamento do fenômeno e outros segmentos de sua engrenagem entram em contato com uma subjetivação ainda mais veemente ocasionada pelo arrefecimento das resistências de estilo e o volume de informações que cresce: o aumento na circulação e na divulgação de informações faz com que a moda atinja um número maior de pessoas que manipulam ativamente seus códigos. A Moda torna-se um elemento integrante das condições de subjetivação, exprimindo e compondo construções identitárias (MOTA, 2008). Os terrenos que a Moda atravessa evidenciam suas variadas interpretações: "Moda é sonho que veste a realidade, é desejo, atitude, expressão pessoal, disfarce. Moda é imagem, constrói imagens, confunde-se com as imagens da mídia, constrói-se com as imagens de marketing" (MESQUITA, 2010, p. 31). Algumas características 
acrescem o sentido de expansão: a Moda é exibida pela mídia, sendo veiculada para públicos de todas as classes; e o paradoxo entre a padronização e a diferenciação questiona a própria noção de Moda. O paradoxo desdobra-se à medida que a liberdade de escolha dá autonomia criativa ao sujeito e o mundo das marcas de renome afirma-se cada vez mais. Os níveis adiantados de efemeridade, esteticismo e individualidade, que caracterizam a instauração e a continuidade da estrutura da Moda, atravessam paradigmas culturais, ao romperem com estruturas lineares.

A efemeridade é difundida por uma rede de contatos e informações conduzida por uma velocidade mais reduzida graças às versões atualizadas dos meios de comunicação e à demanda por tecnologias mais avançadas. O intervalo entre o fato e a sua divulgação é reduzido ao máximo possível. O esteticismo não está mais conectado somente à noção de sujeito, pois se estende à própria dinâmica da Moda: ao passo que a imagem "de moda dos anos 1990 habita terrenos menos aprisionados à roupa em si e mais ligados à sensibilidade do espectador, à subjetividade" (MESQUITA, 2010, p. 36). Para Mesquita (2010), a liberdade proposta pelo individualismo não é somente prevista a partir do poder de escolha ofertado pelo consumo, pois já é reconhecida mediante uma invenção de universos particulares: a montagem de estilos pessoais pela seleção de produtos de procedências distintas, sejam originais ou cópias.

A Moda aflora vontades subjetivas, guiadas por um fluxo que movimenta informações e pessoas a partir duma coesão social com ingerências normativas, sem padrões necessários de rótulos. A Moda, ao estabelecer padrões e uniformidade dentro dum grupo, funciona da mesma forma como um mecanismo libertador, ao permitir que seja rompida essa uniformidade, sendo a moda adotada curiosamente quando ainda não se tornou moda (BARBOSA, 2008). Rocamora e Smelik (2015) definem a Moda como um sistema intangível de significação promovido por agentes coletivos e individuais unidos por práticas de produção, distribuição, consumo e representação. Do ponto de vista econômico, Kawamura (2005) afirma que a Moda pode ser resultado duma conspiração em que parte dos produtores de roupas fazem com que o consumidor desembolse mais dinheiro para a indústria. Seriam os designers que impõem novas modas no intuito de estimular o mercado. Essa explicação, para a autora, é simplista e não abrange aspectos sociológicos porque uma cultura que envolve a dinâmica da Moda não depende exclusivamente do montante de capital gasto, já que cobre circunstâncias de fundamento simbólico e valores que dizem respeito, sobretudo, à forma como se constitui uma dada sociedade, já que a Moda, para além do aspecto econômico, potencializa relações entre o indivíduo e seus diversos círculos sociais.

A Moda constitui-se "de um jogo, dentro do qual os seus agentes se legitimam, de acordo com o cumprimento, ou não, das regras previamente estabelecidas" (MARQUES, 2014, p. 56). Segundo Simmel (2014), o jogo é uma disputa social, em que a imitação se torna um lance, ao satisfazer a fusão do indivíduo na generalidade. Esse jogo que a Moda promove se sus- 
tenta na probabilidade de mudanças, adaptando ou rejeitando novidades. Nesse jogo, a vida, representada por um pião, ora é uma peça da partida no tabuleiro, seguindo orientações de uma jogada; ora coordena seu destino, oscilando "entre a unidade do todo e o ser-para-si de cada elemento do mundo, entre hereditariedade e variabilidade, entre a ordem social e o destino individual" (MORÃO, 2014, p. 11). O tabuleiro é organizado por uma sinergia de forças contrárias. Enquanto o pião é orientado, uma força dominante faz com que siga algumas regras do jogo; já quando coordena, pode burlar e adaptar regras, como também desenvolver suas próprias. Os participantes são posicionados no tabuleiro em conformidade com seu nível, adequando-se a cada lance, cumprindo indicações e prescrições duma rodada e outra. As decisões em favor dum determinado resultado dependem das funções exercidas nesse jogo, indicando as posições que cada jogador tem no tabuleiro.

\section{Considerações finais}

A partir de teorias como o efeito trickle down, a luta de classes torna simplista a ideia de Moda. Considerando a imprevisibilidade pautada, o polo dualista entre ricos versus pobres, influenciadores versus influenciados, inovadores versus copistas caem por terra, uma vez que tal polo insiste a respeito duma cultura dualista que opõe o bem e o mal, como se fossem categorias unicamente distintas para que se possa entender a realidade. A postura dualista, por vezes maniqueísta, fruto duma cultura ocidental, constrói uma visão que pode trazer consequências mais lesivas e onerosas à compreensão dum pensamento democrático.

A compreensão duma Moda que se baseia num efeito de unidireção dirige-se a um pensamento mais conservador, ao procura categorizar e dividir uma estrutura simbólica a partir de polos distintos e que não se misturam, o que demonstra um alerta para a potencialização do aumento da divisão de classes e da desigualdade social. 0 discurso que traz a Moda considerando um sentido vertical busca por meio de sutilezas a determinação de arquétipos, exemplos e padrões instituídos por modelos de grupos socialmente dominantes. Por essa razão, é relevante articular teorias contemporâneas que inovam sobre o design de moda, com o intuito de priorizar um pensamento que discorde da luta de classes, objetivando aclarar mais a abertura para a discussão sobre a igualdade social. Tal discussão deve ser oportuna em diversos parâmetros e estruturas onde possa ser altercada, seja na indústria, no mercado e, sobretudo, no ambiente acadêmico. É nesse último que as proposições aqui explanadas sobre a reunião de pensadores voltados para a exaltação da subjetividade indicam um ponto inicial para sobreavisar relativamente às categorizações que podem incidir em torno de um dualismo vertical. Os discursos, elaborados em concordância com sua projeção e importância, são basilares para a construção dum modelo social. 
Dada essa assertiva, a discussão aqui proposta indica que teorias que ainda possam vir a ser representativas do efeito trickle down aguilhoam habilmente a estrutura duma moda expandida. $O$ design de moda, ao abranger uma indústria mundial de poder avassalador, é integrado por profissionais que podem ser habilitados por um pensamento simplista e conversador do funcionamento vertical da Moda. Esse pensamento prioriza um estabilidade do funcionamento dum sistema que afeta a disparidade duma estrutura, ao defender normas desiguais à propriedade industrial e ao desmantelamento de culturas tradicionais, por exemplo. A projeção dum discurso assim traz tais consequências quando penetra a edificação de modelos que preferem por estabilizar normas, ao contrário de permitir a exaltação da liberdade e da subjetividade.

Assim sendo, a emergência duma teoria contemporânea para o design de moda deve ser ressaltada com a finalidade de estimular o reconhecimento da subjetividade no âmbito do ensino e da indústria para que não apenas um modelo, porém a diversidade de distintas propostas possa se contrapor à estabilidade de normas sociais. As normas estáveis esquivam-se da forma da Moda expandida. As fronteiras estabelecidas diluem-se para desformatar estilos, compondo trajetórias infinitas impulsionadas pela difusão das cópias na vida social. o design de moda, desde meados da década de 1990, estaria personificado num corpo que veste variados estilos: da marca famosa às relíquias dum brechó, da mala Louis Vuitton aos óculos Ray-Ban comprados na feira ou do cinto Diesel adquirido no comércio ambulante. $O$ contrassenso é uma das circunstâncias que altera o conceito de Moda, tornando-o mutável, relativo e imprevisível.

\footnotetext{
1 Para mais informações sobre outras fases da referida pesquisa, cf. Lopes (2019a; 2019b).

2 A obsolescência programada refere-se ao tempo de durabilidade dum produto até o momento de seu descarte por perder sua funcionalidade (PINHEIRO; MATOS; LOPES, 2014).

3 Sobre as variações a respeito do tempo que Pelbart declara, cf. também Vida capital: ensaios de biopolítica (2003) do mesmo autor.

4 Em sua dissertação de mestrado, Mesquita (2000) chega a atentar para um fenômeno semelhante, o qual denomina de Moda movediça.
} 


\section{Referências}

AGAMBEN, Giorgio. O que é contemporâneo? e outros ensaios. Chapecó: Argos, 2009.

BALDINI, Massimo. A invenção da moda: as teorias, os estilistas, a história. Lisboa: Edições 70, 2006.

BARBOSA, Lívia. Moda e estilo de vida. Revista da ESPM, pp. 16-23, set.-out. 2008.

BARNARD, Malcom. Moda e comunicação. Rio de Janeiro: Rocco, 2003.

BLUMER, Hebert. Fashion: from class differentiation to collective sellection. The Sociological Quartely, n. 3, jun. 1969.

BOMFIM, G. Fundamentos de uma Teoria Transdisciplinar do Design: morfologia dos objetos de uso e sistemas de comunicação. Estudos em Design, n. 2, dez. 1997.

BRANDINI, Valeria. Vestindo a rua: comunicação, moda \& metrópole. Revista Fronteiras: estudos midiáticos, n. 1, pp. 23-33, jan./abr. 2007.

CRANE, Diane. Fashion and its social agendas: class, gender, and identity in clothing. Chigago: The University of Chicago Press, 2000.

ENTWISTLE, Joanne. The Fashioned Body: Fashion, Dress and Modern Social Theory. 2 ed. Cambridge: Polity Press, 2015.

FRIEDMAN, K. Theory construction in design research: criteria: approaches, and methods. Design Studies, 24, 2003.

GODART, Frédéric. Sociologia da moda. São Paulo: Editora Senac São Paulo, 2010.

KANT, Immanuel. Antropologia pragmatic. Bari: Laterza, 1994.

KAWAMURA, Yunia. Fashionlogy: an introduction to fashion studies. Nova Iorque: Berg, 2005. KNOLL, Susy Bello; ECHEVERRIA, Pamela. La moda, el derecho e la RSE: relaciones e intercambios entre 3 universos. Tiempo Argentino, ano 51, 6 jul. 2014.

LIPOVETSKY, Gilles. O império do efêmero: a moda e seu destino nas sociedades modernas. São Paulo: Companhia das Letras, 2009.

LOPES, Humberto Pinheiro. A cópia, a moda e a propriedade industrial. Revista Biblos, n. 5, pp. 51-69, 2019a.

LOPES, Humberto Pinheiro. Censura das cópias na indústria da moda. Dobras, n. 25, pp. 112128 , abr. $2019 b$.

LOPES, Humberto Pinheiro. Chafurdos em ziguezagues: metodologia de uma pesquisa de moda mediada pela cultura visual. In: Colóquio de Moda, 8, 2012. Anais do 80 Colóquio de Moda.

LOPES, Humberto Pinheiro. Chafurdos na Moda: heróis e vilões na história das cópias. Goiânia: Editora UFG, 2014.

LOPES, Humberto Pinheiro. Prática das cópias: censura e reconhecimento na indústria da moda. Tese (Doutorado em Estudos Contemporâneos) - Instituto de Investigação Interdisciplinar, Centro de Estudos Interdisciplinares do Século XX, Universidade de Coimbra, Coimbra, 2017.

MANDEVILLE, Bernard. La favolla delle api. Bari: Laterza, 1987.

MARQUES, Cyntia Tavares. Do estilismo ao design: os currículos do bacharelado em moda da Universidade Federal do Ceará. Tese (Doutorado em Educação) - Faculdade de Educação, Universidade Federal do Ceará, Fortaleza, 2014.

MESQUITA, Cristiane Ferreira. Incômoda moda: uma escrita sobre roupas e corpos instáveis. Dissertação (Mestrado em Psicologia Clínica), Pontifícia Universidade Católica de São Paulo, São Paulo, 2000.

MESQUITA, Cristiane Ferreira. Moda contemporânea: quatro ou cinco conexões possíveis. 1 ed. São Paulo: Editora Anhembi Morumbi, 2010. 
MESQUITA, Cristiane Ferreira. Políticas do vestir: recortes em viés. Tese (Doutorado em Psicologia Clínica) - Pontifícia Universidade Católica de São Paulo, São Paulo, 2008.

MESQUITA, Cristiane Ferreira. Projeto Cuide-se: práticas em clínica ampliada e design de moda. In: Congresso Internacional de Moda e Design, 3, Buenos Aires, 9 a 12 maio 2016. Proceedings CIMODE 2016: 3o Congresso Internacional de Moda e Design. Guimarães: Universidade do Minho, Escola de Engenharia, 2016. pp. 1100-106.

MEYER, Guilherme Côrrea. Reflexões sobre a caracterização da pesquisa científica e da prática profissional no design. Estudos em Design, n. 2, 2010.

MORA, Emanuela; ROCAMORA, Agnès, VOLONTÉ, Paolo. The internationalization of Fashion Studies: Rethink the peer-revewing process. International Journal of Fashion Studies, n. 1, pp. 3-17, 2014.

MORÃO, Artur. Introdução: A Moda como sintoma antropológico em Georg Simmel. In: SIMMEL, Georg. Filosofia da moda e outros escritos. Lisboa: Edições Texto \& Grafia, Lda., 2014. MOTA, Maria Dolores de Brito. Moda e Identidade: aspectos psicossociais da roupa na contemporaneidade. Actas de Diseño, n. 1, pp. 188-189, 2006.

MOTA, Maria Dolores de Brito. Moda e subjetividade: corpo, roupa e aparência em tempos ligeiros. Modaplavra e-periódico, n. 2, pp. 21-30, ago.-dez. 2008.

MOTTA, Eduardo. Do objeto de moda à narrativa. In: PRECIOSA, Rosane; MESQUITA, Cristiane (org.). Moda em ziguezague: interfaces e expansões. São Paulo: Estação das Letras e Cores, 2011.

PELBART, Peter Pál. A vertigem por um fio. São Paulo: Editora Iluminuras Ltda., 2000.

PELBART, Peter Pál. Desvios do tempo. In: PRECIOSA, Rosane; MESQUITA, Cristiane (org.). Moda em ziguezague: interfaces e expansões. São Paulo: Estação das Letras e Cores, 2011.

PELBART, Peter Pál. Vida capital: ensaios de biopolítica. São Paulo: Iluminuras, 2003.

PINHEIRO, Natália Parente, MATOS, Cynthia de Holanda Sousa; LOPES, Humberto Pinheiro. O consumo de produtos de moda visto a partir de experiências de ócio. Projetica, n. 2, pp. 19-32, 2014.

PRECIOSA, Rosane. Produção estética: notas sobre roupas, sujeitos e modos de vida. São Paulo: Editora Anhembi Morumbi, 2005.

RIELLO, Giorgio. Breve historia de la moda: Desde la Edad Media hasta la actualidad. Barcelona: Editorial Gustavo Gilli, 2016.

ROCAMORA, Agnès; SMELIK, Anneke. Thinking Through Fashion: A Guide to Key Theorists. [s. 1.]: I. B. Tauris \& Co Ltd, 2015.

SERRAL, Isabelle; MESQUITA, Cristiane. O corpo encontra a roupa: Design de moda entre normatização e utopia. DATJournal, n. 3, pp. 52-75, 2019.

SIMMEL, Georg. Fashion. The American Journal of Sociology, n. 6, pp. 541-558, maio 1957. SIMMEL, Georg. Filosofia da moda e outros escritos. Lisboa: Edições Texto \& Grafia, Lda., 2014.

SOUZA, Gilda de Mello e. O espírito das roupas: a moda no século XIX. São Paulo: Companhia das Letras, 1987.

SPENCER, Hebert. Principi de Sociologia. Turim: Utet, 1967.

SVENDSEN, Lars. Filosofia do tédio. Rio de Janeiro: Jorge Zahar Ed., 2006.

SVENDSEN, Lars. Moda: uma filosofia. Rio de Janeiro: Zahar, 2010.

TARDE, Gabriel. Les lois de l'imitation. Paris: Felix Alcam, 1890.

Recebido: 30 de dezembro de 2020. Aprovado: 10 de fevereiro de 2021.
VEBLEN, Thorstein. The theory of leisure class: an economic study of institutions. Londres: McMillan \& Co. Ltd., 1915. 